\title{
Decrease in Saturation Density of Mammalian Carcinoma Cell Culture during Exposure to Bestatin, a Clinically Applicable Agent
}

\author{
Shinichi Okuyama and Hitoshi Mishina \\ Department of Radiology, Tohoku Rosai Hospital, Sendai \\ 980
}

\begin{abstract}
Okuyama, S. and Mishina, H. Decrease in Saturation Density of Mammalian Carcinoma Cell Culture during Exposure to Bestatin, a Clinically Applicable Agent. Tohoku J. exp. Med., 1984, 142 (3), 349-350— Bestatin, one of the small molecular products of Streptomyces olivoreticuli, and a potential immunostimulator, was shown to decrease the saturation density of murine carcinoma cell culture. The finding may indicate a possibility of direct action of bestatin upon cancer cells presumably resulting in cancer cell redifferention. — bestatin; cancer cell redifferentiation; decrease in saturation density
\end{abstract}

Any agents or measures decreasing the saturation density of mammalian carcinoma cell cultures may affect cellular proliferation (Goto et al. 1972) and induce cancer cell redifferentiation (Awano and Matsuzawa 1977; Okuyama et al. 1978). We have suggested that binding of gallium ions onto the cancer cell surface as much as to neutralize the negative charge may contribute to such redifferetiation (Okuyama et al. 1983).

Bestatin is primarily an inhibitor of leucine aminopeptidase B, and is potentially capable of binding to ubiquitous hydrolytic enzymes (Umezawa 1980). It is therefore expected that this agent induces a reduction of the saturation density of mammalian carcinoma cell cultures.

FM3A undifferentiated mammary adenocarcinoma cells of the mouse were cultured in Eagle's MEM ( $\mathrm{Ca}^{2+}$ minus) medium supplemented with calf serum to $10 \%$. The incubation was performed by a standard $\mathrm{CO}_{2}$ technique. Thirty $\mathrm{mg}$ of bestatin was dissolved in $10 \mathrm{ml}$ of distilled water, and subsequent dilution was made with normal saline for dose studies. Cell suspensions consisted of $1-1.5 \times 10^{4}$ cells per ml. Marginal cell kill was observed (Fig. 1). When the cluture was exposed to $300 \mu \mathrm{g}$ of bestatin per ml, the cell multiplication was still observed. However, a decrease in the saturation density occurred beyond day-3 (Fig. 2). Administration at this point of a second appropriate agent that is capable of orienting cellular differentiation may help inducing redifferentiation among those cells thus treated.

Received for publication, July 1, 1983.

Request for reprints to: Shinichi Okuyama, Department of Radiology, Tohoku Rosai Hospital, Sendai 980, Japan. 


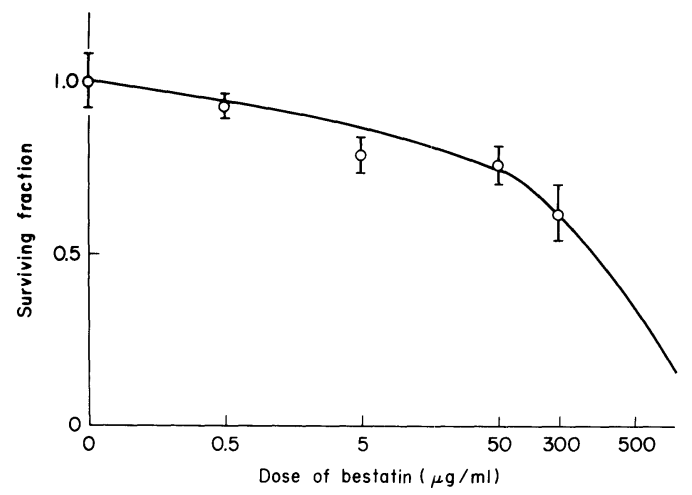

Fig. 1. Dose response of FM3A undifferentiated murine mammary adenocarcinoma cells to bestatin in vitro. Maginal cell kill was observed. mean \pm S.D.

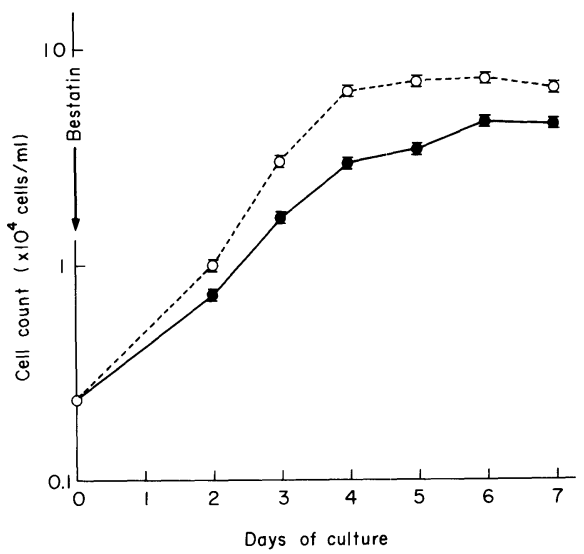

Fig. 2. Temporal response of FM3A undifferentiated murine mammary adenocarcinoma cells to bestatin in vitro. A decrease in saturation density was seen beyond day-3. mean \pm s.D. $\bigcirc \cdots O$, saline control; $\bullet-\bullet$, bestatin added.

\section{References}

1) Awano, T. \& Matsuzawa, T. (1977) Accumulation and biological effects of gallium in malignant cell lines in vitro. Jpn. J. nucl. Med., 14, 73-81.

2) Goto, M., Kataoka, Y. \& Sato, H. (1972) Decrease of saturation density in cultured tumor cells by dextran sulfate. Gann, 63, 371-374.

3) Okuyama, S., Sato, T., Takahashi, K. \& Matsuzawa, T. (1978) Gallium modification of cancer biology: Experimental studies on V2 rabbit carcinoma. Sci. Rep. Res. Inst. Tohoku Univ.-C (Med.), 25, 58-64.

4) Okuyama, S., Sano, M., Awano, T., Takeda, S., Yamada-Yokoyama, K., Takahashi, K. \& Matsuzawa, T. (1983) Gallium induces reduction of negative charge of the cell membrane and redifferentiation of cancer cells. Tohoku J. exp. Med., 142, 347-348.

5) Umezawa, H. (1980) Screening of small molecular microbial products modulating immune responses and bestatin. In: Recent Results in Cancer Research, Vol. 75, Springer-Verlag, Berlin, pp. 115-125. 